\title{
A single origin for the most frequent mutation causing late infantile metachromatic leucodystrophy
}

Joel Zlotogora, Yael Furman-Shaharabani, Ann Harris, Maria Luiza Barth, Kurt von Figura, Volkmar Gieselmann

\begin{abstract}
Metachromatic leucodystrophy is an autosomal recessive degenerative disease of the nervous system caused by the deficiency of the lysosomal enzyme arylsulphatase A (ARSA). We report here on the high incidence of late infantile MLD among Muslim Arabs originating from Jerusalem, most probably because of a founder effect. All the patients were found to be homozygous for $459+1 \mathrm{G} \rightarrow \mathrm{A}$, a mutation which destroys the splice donor site of exon 2 of the ARSA gene. This mutation has been reported to be the most common mutation causing MLD.

We studied the ARSA haplotype defined by three intragenic polymorphic sites in DNA samples from Muslim Arab patients from Jerusalem, a Christian Arab patient originating from the region, and eight other white patients, all homozygous for the $459+1 \mathbf{G} \rightarrow A$ mutation. All the alleles carried the same haplotype which is in complete linkage disequilibrium with the mutation. This finding indicates a common origin for the $459+1 \mathrm{G} \rightarrow \mathrm{A}$ mutation which may have been introduced into Jerusalem at the time of the Crusades.
\end{abstract}

( $(\mathcal{M}$ Med Genet 1994;31:672-674)

University, Jerusalem Israel

J Zlotogora

Y Furman-Shaharabani

Paediatric Molecular Genetics, Institute of Molecuiar Medicine, Oxford University,

John Radcliffe

Hospital, Oxford OX3

9DU, UK

A Harris

Division of Medical and Molecular

Genetics, UMDS-

Guy's Campus,

London SE1 9RT, UK

M L Barth

Department of

Biochemistry II,

Georg-August

University, Gottingen,

Germany

$\mathrm{K}$ von Figura

V Gon Figura

Correspondence to

Dr Zlotogora, Department of Human Genetics,

Hadassah Medical Center,

POB 12000, Jerusalem,

Israel 91120 .

Received 3 November 1993

Revised version accepted for publication 28 March 1994 Metachromatic leucodystrophy (MLD) is a neurodegenerative disease most commonly caused by the deficiency of the lysosomal enzyme arylsulphatase A (ARSA). ${ }^{1}$ According to the age of onset the disease is classified into three forms: the late infantile and juvenile forms which are the most common and the adult form which is rare. The disease is found in all populations and its incidence is estimated to be 1 in 40000 live births.

The ARSA gene is located in $22 \mathrm{q} 13$ and is about $3 \cdot 2 \mathrm{~kb}$ long with a coding sequence of $1521 \mathrm{bp}^{2}$ Mutations in the ARSA gene may lead to the deficiency of ARSA causing MLD. In addition, a very low activity of ARSA can be found in persons without clinical symptoms, a phenomenon referred to ARSA pseudodeficiency (PD). The most common mutation causing MLD, $459+1 \mathrm{G} \rightarrow \mathrm{A}$, is a $\mathrm{G} \rightarrow \mathrm{A}$ transition destroying the splice donor site of exon 2 . This mutation is associated with a severe phenotype of MLD and has never been found venile or adult MLD. Among 56 white patients affected with late infantile MLD, the $459+1$ $\mathrm{G} \rightarrow \mathrm{A}$ allele was found in 41 alleles $(37 \%$ of the mutant alleles) ${ }^{3-5}$ while in seven patients originating from Japan, none had the mutation. ${ }^{6}$ The mutation was also found in 14 alleles among 34 patients affected with juvenile MLD ( $20 \%$ of the mutant alleles). ${ }^{34}$

We report on the high incidence of the mutation $459+1 \mathrm{~A} \rightarrow \mathrm{G}$ in the region of Jerusalem and on a study of the origin of this mutation in white patients.

\section{Material and methods}

SCREENING FOR THE $459+1 \mathrm{~A} \rightarrow \mathrm{G}$ MUTATION

During the last 15 years 27 patients have been diagnosed as being affected with late infantile MLD in the Department of Human Genetics at Hadassah Medical Centre. The diagnosis was based on clinical investigations and deficiency of ARSA in leucocytes and fibroblasts. These 27 patients originated from 17 unrelated families, four Jewish and 13 Arabs. Three of the Muslim Arab patients originated from Jerusalem. This represents a very high incidence, since in this period fewer than 50000 Muslim Arab children were born in Jerusalem.

DNA samples from these patients were tested for the $459+1 \mathrm{G} \rightarrow \mathrm{A}$ mutation using an $\mathrm{MvaI}$ polymorphism which is abolished by the mutation. The primers used for the amplification were $5^{\prime}$ AGC CGG TGC CAG TGG AGG in the homozygous state in patients with ju-
HAPLOTYPES USING THREE POLYMORPHISMS

Three intragenic polymorphic sites have been described within the ARSA gene: a $B g l$ site in exon 3, a BsrI site in exon 7, and a BamHI site in intron 7 . The polymorphisms were determined as previously described after the amplification of the ARSA gene in two fragments (Zlotogora et al, submitted). In a previous study we showed that the PD allele is in complete linkage disequilibrium with the haplotype $(B g l \mathrm{I}$ (2), BsrI (2), BamHI (1)) and that the mean frequency of each of the polymorphisms in 

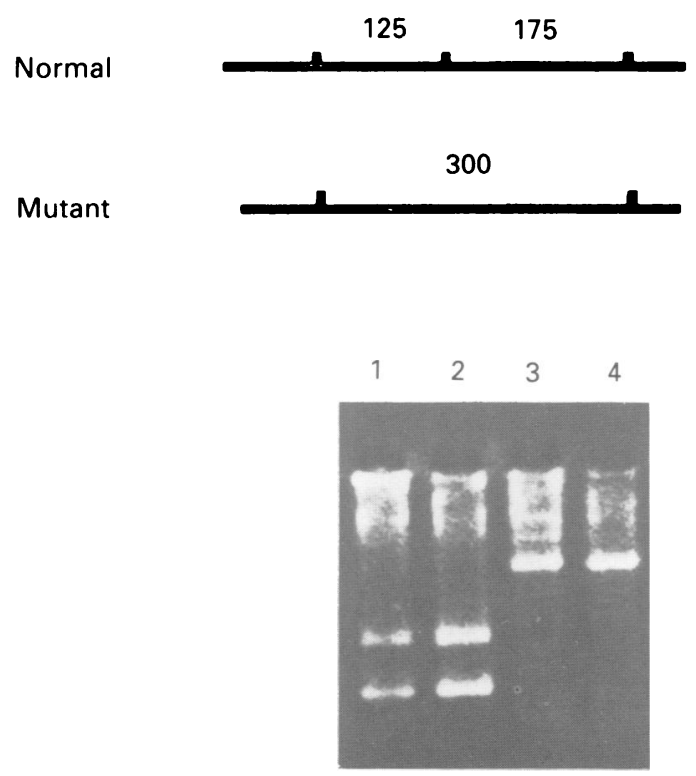

Digestion of a 350 bp fragment with Mval. The $459+1$ $G \rightarrow A$ mutation abolishes the restriction site. Two fragments of 125 and $175 \mathrm{bp}$ are seen in normal persons (lanes 1,2 ) while only one fragment of $300 \mathrm{bp}$ is seen in homozygotes for the mutation (lanes 3, 4).

non-PD alleles among random whites is $B g I I$ (1) $9.6 \%, B s r I$ (1) $54.4 \%$, and $B a m H I$ (1) $74.9 \%$ (Zlotogora et al, submitted).

The intragenic polymorphisms were determined in three DNA samples from homozygous MLD patients from Israel as well as the DNA from both heterozygous parents of a fourth MLD patient. In addition we examined DNA samples from eight homozygotes for $459+1$ $\mathrm{G} \rightarrow \mathrm{A}$ originating from Europe and the USA.

\section{STATISTICAL ANALYSIS}

In the analysis of the results the $\chi^{2}$ test was used.

\section{Results}

Among the 27 patients with late infantile MLD originating from 17 unrelated families, four unrelated Arab patients (three Muslims and one Christian) were found to be homozygous for $459+1 \mathrm{G} \rightarrow \mathrm{A}$. This was determined by DNA analysis in three patients, while since no DNA was available from another unrelated Muslim Arab patient, both parents were examined and found to be heterozygous for the mutation.

All the three Muslim Arab patients originated from the same small village, which relatively recently has been included in the municipality of Jerusalem. Each of the patients was born to first cousin parents, and no relationship was known between the different families. The fourth patient was a Christian Arab from a small town situated a few kilometres from Jerusalem.

\section{INTRAGENIC ARSA HAPLOTYPES IN} HOMOZYGOTES FOR THE $459+1 \mathrm{G} \rightarrow$ A ALLELE The three Arab patients homozygous for the $459+1 \mathrm{G} \rightarrow \mathrm{A}$ allele in whom DNA was avail- able were homozygous for each of the three polymorphisms determining the haplotype associated with the $459+1 \mathrm{G} \rightarrow \mathrm{A}$ allele: ( $B g l \mathrm{I}$ (1), BamHI (1), BsrI (1)). Examination of the polymorphisms in the DNA samples from the parents of the fourth patient did not allow construction of haplotypes since each of them was heterozygous at most of the sites. However, the results were compatible with the child being homozygous for the same haplotype.

The eight patients homozygous for the $459+1 \mathrm{G} \rightarrow \mathrm{A}$ allele from Europe and the USA were also homozygous for each of the three polymorphisms having the same haplotype associated with the $459+1 \mathrm{G} \rightarrow \mathrm{A}$ allele: $(B g l \mathrm{I}$ (1), BamHI (1), BsrI (1)).

LINKAGE DISEQUILIBRIUM BETWEEN THE $459+1$ $\mathrm{G} \rightarrow \mathrm{A}$ ALLELE AND THE HAPLOTYPE ( $B g l \mathrm{I}(1)$, $B a m$ HL (1), BsrI (1))

The frequency of the three polymorphisms on the normal ARSA alleles was compared to their frequency on 20 alleles with the mutation $459+1 \mathrm{G} \rightarrow \mathrm{A}$ (alleles from the eight patients from Europe and the USA, the Christian Arab patient, and one of the Muslim Arab patients). The difference was highly significant for $B g l I$ $(\mathrm{p}<0.001), \quad B s r \mathrm{I} \quad(\mathrm{p}<0.001)$, and $B a m \mathrm{HI}$ $(\mathrm{p}<0.01)$. In the general population, the frequency of the haplotype (BgII (1), BamHI (1), $B s r I$ (1)) was calculated to be $3.9 \%$ and this is significantly different from its frequency in the $459+1 \mathrm{G} \rightarrow \mathrm{A}$ alleles $(\mathrm{p}<0 \cdot 0001)$.

\section{Discussion}

Late infantile MLD is a relatively rare disease and therefore, even though $459+1 \mathrm{G} \rightarrow \mathrm{A}$ is the most frequent mutation causing the disorder, it is still rare among white populations. This is the first report of a community with a high incidence of this mutation.

The three Muslim Arab patients homozygous for the mutation $459+1 \mathrm{~A} \rightarrow \mathrm{G}$ originated from a small village which was relatively recently included within the municipality of Jerusalem. In this part of the Middle East, most of the villages were founded by only a few persons and marriages are by tradition within the family; first cousin marriages are, by preference, the most frequent. ${ }^{7}$ Therefore, even though the families of the patients do not know of any relationship between them, it may be assumed that they have common ancestors and that the mutation originates from a common founder. On the other hand, the fourth patient who was from a close geographical region was born into a Christian family. Since inter-religious marriages are very rare, a common founder is improbable. In addition, since there are only a few thousand original inhabitants of the village, the incidence of the mutation among them is probably very high. However, there have been many changes in the distribution of the population since the village was included within the municipality of Jerusalem and the mutation probably began to be spread among Muslims. In order to determine the frequency of the mutation, we plan a screening programme of 
this population at risk. Such screening will also allow appropriate genetic counselling.

When first reported, the $459+1 \mathrm{G} \rightarrow$ A allele was completely sequenced in one compound heterozygote patient ${ }^{4}$ and the haplotype was found to be (BglI (1), BamHI (1), BsrI (1)). Therefore in 21 alleles (the allele sequenced and 20 alleles from 10 homozygotes) with the $459+1 \mathrm{G} \rightarrow \mathrm{A}$ mutation, there was complete linkage disequilibrium between the allele carrying the mutation and a haplotype defined by three different intragenic polymorphic sites. This haplotype (BgII (1), BamHI (1), BsrI (1)) is rare in the general population $3.9 \%$ of alleles) and the linkage disequilibrium is highly significant. The finding of a single haplotype in all the $459+1 \mathrm{G} \rightarrow \mathrm{A}$ alleles suggests a common origin for all the carriers. Since both Muslim and Christian patients have been diagnosed in the region of Jerusalem, this may suggest that the mutation was introduced in Jerusalem at a period when both migration and religious conversion were frequent. For instance, the mutation may have been introduced from Europe at the time of the Crusades in the 11th and 12th centuries. Further knowledge of the distribution of the mutation is needed in order to understand its origin better.

Three other mutations which cause late infantile MLD have been reported to be frequent, each in a particular population. The G99D mutation was found in eight out of 12 alleles from Japanese patients ( $66 \%$ of mutant alleles) but up to now has not been found in white populations. ${ }^{5}$ In Australia a mutation, T274M, was found in the homozygous state in six patients of Lebanese origin. ${ }^{6}$ The same mutation was also found in two Israeli Christian Arabs from the Galilee and most probably has a common origin in Lebanon (in preparation). The third mutation, L377P, which occurred on the PD allele background, was found to be very frequent because of a founder effect in an isolate, the Habbanite Jews ( $17 \%$ carrier frequency), and relatively frequent among the Yemenite Jews who were living in the same geographical region (Zlotogora et al, submitted). The other mutations causing late infantile MLD which have been reported so far are rare or unique.

From the analysis of the different mutations causing late infantile MLD it seems that the difference between the mutation $459+1 \mathrm{G} \rightarrow \mathrm{A}$ and the other relatively frequent mutations is that $459+1 \mathrm{~A} \rightarrow \mathrm{G}$ first occurred in Europe, a continent in which and from which migration has been frequent. The other mutations occurred in populations which have been, up to recently, relatively isolated and therefore have not yet spread among other populations.

This research was supported by a grant from the GIF, the German Israeli Foundation for Scientific Research and Development.

1 Kolodny EH. Metachromatic leukodystrophy and multiple sulfatate deficiency: sulfatide lipidosis. In: Scriver CR, Beaudet AL, Sly WS, Valle D, eds. The metabolic basis of inherited disease. 6th ed. Vol 2. New York: McGraw-Hill, 1989:1721-50.

2 Kreysing J, von Figura K, Gieslemann V. Structure of the human arylsulfatase A gene. Eur $\mathcal{F}$ Biochem 1990;191: 627-31.

3 Barth ML, Fensom A, Harris A. Prevalence of common mutations in metachromatic leukodystrophy patients in Britain. Hum Genet 1993;91:73-7.

4 Polten A, Fluharty AL, Fluharty CB, Kappler J, von Figura $\mathrm{K}$, Gieselmann V. Molecular basis for the different forms of metachromatic leukodystrophy. $N$ Engl F Med 1991;324: $18-22$.

5 Caillaud C, Blanchot C, Akli S, et al. Molecular basis of late infantile metachromatic leukodystrophy in France. 9th ESGLD Workshop, Greece, 1993:A95.

6 Hasegawa Y, Kawame H, Eto Y. Mutations in the arylsulfatase A gene of Japanese patients with metachromatic leukodystrophy. DNA Cell Biol 1993;12:493-8.

7 Freundlich E, Heino N. Consanguineous marriage among rural Arabs in Israel. Isr f Med Sci 1984;20:1035-8.

8 Harvey JS, Nelson PV, Carey WF, Robertson EF, Morris CP. An arylsulfatase A (ARSA) missense mutation (T274M) causing late-infantile metachromatic leukodystrophy. Hum Mutat 1993;2:261-7. 